\title{
Article
}

\section{Investigative Cases and Student Outcomes in an Upper-Division Cell and Molecular Biology Laboratory Course at a Minority-serving Institution}

\author{
Jonathan D. Knight, ${ }^{*}$ Rebecca M. Fulop, ${ }^{* \dagger}$ Leticia Márquez-Magaña, ${ }^{*}$ \\ and Kimberly D. Tanner*t
}

*Department of Biology and ${ }^{\dagger}$ Science Education Partnership and Assessment Laboratory, San Francisco State University, San Francisco, CA 94132

Submitted June 13, 2008; Revised August 11, 2008; Accepted August 28, 2008

Monitoring Editor: Martha Grossel

\begin{abstract}
Active-learning strategies are increasingly being integrated into college-level science courses to make material more accessible to all students and to improve learning outcomes. One activelearning pedagogy, case-based learning (CBL), was developed as a way to both enhance engagement in the material and to accommodate diverse learning styles. Yet, adoption of CBL approaches in undergraduate biology courses has been piecemeal, in part because of the perceived investment of time required. Furthermore, few CBL lesson plans have been developed specifically for upper-division laboratory courses. Here, we describe four cases that we developed and implemented for a senior cell and molecular biology laboratory course at San Francisco State University, a minority-serving institution. To evaluate the effectiveness of these modules, we used both written and verbal assessments to gauge learning outcomes and attitudinal responses of students over two semesters. Students responded positively to the new approach and seemed to meet the learning goals for the course. Most said they would take a course using CBL again. These case modules are readily adaptable to a variety of classroom settings.
\end{abstract}

\section{INTRODUCTION}

Despite a wealth of career opportunities in science and engineering, undergraduates switch out of these majors nearly twice as often as they leave humanities majors (Seymour and Hewitt, 1997; Hayes, 2002). Students who identify as underrepresented minorities (URMs) - African Americans, Native Americans, Hispanics, and Pacific Islandersare particularly likely to steer clear of science careers (Summers and Hrabowski, 2006). Members of these groups earn only $14.6 \%$ of biology and $11 \%$ of physics bachelor's degrees, according to the most recent data available from the National Center for Education Statistics (2005-2006), while earning $24.8 \%$ of liberal arts degrees, a percentage which is more in line with the proportion of URMs in the general population (Rath et al., 2007).

DOI: $10.1187 /$ cbe. $08-06-0027$

Address correspondence to: Jonathan D. Knight (jknight@sfsu.edu).
Much of this attrition seems to be the result of poor pedagogy. According to the most extensive survey to date of the causes of attrition, the three main reasons students leave science are 1) loss of interest, 2) desire for a better education, and 3) poor teaching by science faculty (Seymour and Hewitt, 1997). These factors are deeply intertwined. Students in the survey reported taking more interest in the collaborative learning approaches offered by the humanities. They also said they learned more through reading and discussion than they would in the traditional lecture and test mode of most science classes. Indeed, nearly all those who switched out of a science major $(90 \%)$ mentioned poor teaching of science as a concern, as did an alarming $74 \%$ of those who remained in science.

Active learning is believed to improve retention of ideas, particularly for URM students, and it seems to better equip students for critical thinking and collaborative work (Handelsman et al., 2004; DiCarlo, 2006). In one form of active learning, students collaboratively address problems raised 
by a "case," which is typically a short topical story describing a conflict, mystery, or controversy. They generate their own questions and work out how to find answers, ultimately reporting to the class or to the instructor what they have found. In addition to inciting greater interest among students, case-based learning (CBL) and the closely related approach known as problem-based learning (PBL) have advantages for URM students and those who may not learn best through lectures and textbook readings (Chamany et al., 2008). Indeed, CBL and PBL have been considered promising teaching approaches to help overcome barriers rooted in cultural and preparatory differences.

Yet, several challenges have conspired to limit the spread of these pedagogies. Teaching faculty worry that devoting time to collaborative inquiry will reduce the amount of material they can cover. They may also worry about student resistance to an unfamiliar teaching method, or even about their own ability to adopt a new approach. But perhaps the most significant obstacle is the initial investment of time and effort needed to develop case modules that will stimulate the necessary degree of inquiry and lead students in the desired direction. For faculty already saddled with substantial teaching and research loads, this can seem prohibitive (Allen and Tanner, 2003; Chamany et al., 2008).

These challenges are compounded in laboratory courses. Not only should the case or problem stimulate inquiry but also it should lead students to design experiments that can be performed in class. Unless experiments are somewhat prescripted, the risk of first-time failure for trivial technical reasons is high. Yet, opportunities to repeat unsuccessful classroom experiments are scarce. Even when all parties are willing, finding a time when full-time undergraduates, busy instructors, and heavily used teaching labs are simultaneously available is problematic. Regardless, courses often work with a preset supply of reagents and equipment, limiting the options for student-led investigations. Indeed, only a few examples of case-based approaches to laboratory courses have been published (Wright and Boggs, 2002; Howard and Miskowski, 2005; Regassa and Morrison-Shetlar, 2007).

At San Francisco State University (SFSU), a minorityserving institution, we participated in a collaborative effort to integrate CBL into the biology curriculum beginning in 2005 with a Course, Curriculum, and Laboratory Improvement (CCLI) grant from the National Science Foundation. A portion of the grant was used to host a campus workshop on case development featuring expert case developers Ethel Stanley, Margaret Waterman, and Katayoun Chamany (Stanley and Waterman, 2000; Chamany, 2006). One product of this effort was the revamping in 2006 of an upper-division cell and molecular biology laboratory course to include a series of case modules that lead into classroom experiments.

Experiments in Cell and Molecular Biology (Biology 351) is required of all biology majors with an emphasis in cell and molecular biology and is normally taken in the fourth year. Techniques introduced include animal cell culture, fluorescence microscopy, gel electrophoresis, Western blotting, microarrays, polymerase chain reaction (PCR), and DNA sequencing. Students communicate their results in several formats, including posters, short research articles, and a public service pamphlet. Our objective was to introduce a case-based approach to this traditionally cook-book labora- tory course, which faces constraints on time and reagents, and to monitor both student attitudes and learning outcomes over several course administrations.

To gauge the success of the new case modules, we collected both written assessment and videotaped interviews with students to determine a variety of student learning outcomes and attitudes toward the CBL pedagogical approach. We report here our experience with the development and implementation of four cases designed to teach laboratory methods to upper-division cell and molecular biology majors. We have evidence that students not only learned the techniques, but also gained problem-solving skills and benefited intellectually and socially. Despite showing initial resistance to the unfamiliar pedagogy, most students came away with positive attitudes toward CBL, saying they would take another course that used it.

\section{METHODS}

\section{Course Overview and Case Design}

Four case modules were introduced in spring and fall 2007 to an upper-division cell and molecular laboratory course at SFSU. Each case module was $2-3$ wk long. The course was held in a laboratory classroom, with a variety of standard cell biology equipment, including three laminar flow hoods, a $\mathrm{CO}_{2}$ incubator, centrifuges, inverted microscopes, thermal cyclers, and electrophoresis rigs. To enroll, students were required to have taken lecture courses in cell biology and genetics. The course was required for all cell and molecular biology majors. For most students, it was the first hands-on exposure to techniques (PCR, electrophoresis, and cell culture) they had only heard about in lecture. The course met for two 4-h sessions a week, but the case modules described here could readily be adapted to other course formats. In the traditional version of the course, the first hour of each session was devoted to lecture and the remaining $3 \mathrm{~h}$ to following laboratory protocols that led to stereotypical data sets. For example, students would hear a talk about the bacterial lac operon and then biochemically assay $\beta$-galactosidase expression in Escherichia coli cultures. In the case-based format, the entire session was considered to be available for experiments, Internet research, class discussion, written exercises, brief student presentations, and occasional short lectures. The four cases summarized below are presented in Table 1 . We made an effort to introduce names and scenarios into the cases that would maximize their cultural relevance for our underrepresented minority students.

Case presentation typically consisted of four phases. First, a student volunteer would read the case to the class. The text of each case (see Supplemental Material) was short enough to be read aloud in $<2 \mathrm{~min}$. Afterward, the group brainstormed $(10 \mathrm{~min})$ what they thought the case was about. For example, the case introducing cytoskeletal dynamics (case 2; see below) elicited topics such as poisons, pathology, tubulin, and murder.

The list of topics served as a springboard for the third exercise, in which students self-assembled into groups of three or four to answer the questions "What do we know?" and "What do we need to know?" The first question prodded students to share their knowledge of the topics related to the case with their team members, giving particular attention to ideas that could help resolve the main puzzle or mystery. In answering the second question, students were instructed to be as specific as possible and to ask questions that they themselves could answer through online research or laboratory experiment. For example, a question about whether the beer brewer in case 3 added priming sugar to the beer before bottling would not have been considered investigable, because the case was fictitious and no further information was available. Such a question could have been recast as "Can an excess of priming sugar cause beer bottles to explode?" Students were given $\sim 30 \mathrm{~min}$ to complete this phase. 


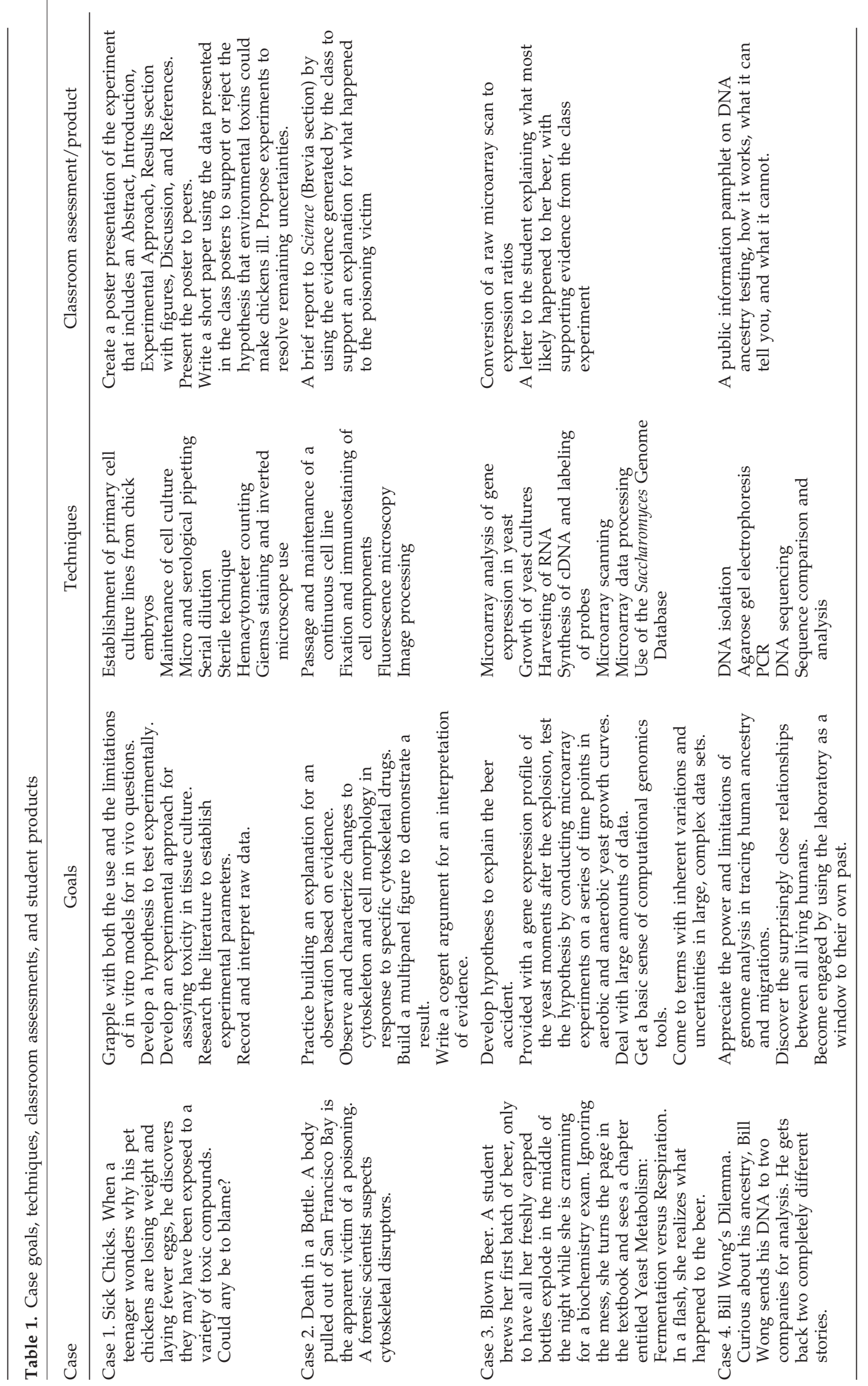


In the fourth phase of case presentation, students reported the results of their group work to the class and then selected questions to research individually or in small groups. The online research was begun in class, but in-class research time was limited to $\sim 30 \mathrm{~min}$ and the work was usually completed at home. Students reported the results of their work to the class in the next period. In some cases, students were allowed to report their research findings on the class instructional website (at SFSU this is an implementation of the Moodle Course Management System called iLearn).

Groups were formed in multiple ways. For the research and discussion phases of the cases, students formed their own groups of four (occasionally a group of three was necessary due to an absence or when the course was underenrolled), most commonly joining bench mates. For the experimental portion of each case, students worked in teams of two. At the beginning of the semester, students chose their own partner. The instructor then assigned new partners (attempting to match complementary strengths and weaknesses, although without describing this to the students) at weeks 5 and 10 of the 15-wk semester.

Each case module took six consecutive 4-h lab periods to complete, with the exception of the human ancestry case, which required only five lab periods. Two noncase-based modules also were presented during the course: one module on cytochemistry and one module on Western blotting.

\section{Case 1: Chick Cell Culture}

The first case, which was added to an exercise using primary chick cell cultures in the traditional offering of the course, described a rural teenager who found that his pet chickens were losing weight and not laying eggs. The teen discovered that they may have been exposed to a potentially harmful household chemical, such as a cleaner, medicine, or pesticide. Students received instruction on how to isolate and grow chick embryonic fibroblasts in culture. In an experiment inspired by a problem-based module described by Howard and Miskowski (2005), each team of two then assayed the growth response of the cells to increasing doses of a potentially toxic household product that they selected and supplied themselves. Examples of products students used include acetaminophen, tobacco, glyphosate (Roundup weed killer), and breath mints. Students conducted background research on their chosen agent to determine appropriate doses for the experiment. After exposing their cell cultures for several days, students assayed changes in cell growth by counting cells with a hemacytometer. They also examined morphological changes in Giemsa-stained cells. Students reported their findings in class by presenting a research poster that formed the basis for student assessment. They then synthesized the poster session and their background research by writing a short essay addressing whether the data presented in class supports the hypothesis that exposure to household compounds could have made the chickens sick.

\section{Case 2: Cytoskeletal Dynamics}

The second case led into an experiment with cytoskeletal disruptors. In this case, two former university classmates discussed a lethal poisoning under investigation at the medical examiner's office where one of the two worked. The characters were given Latino names, Martina and José, in an effort to further engage this population of students. The conversation turned to fungal toxins that disrupt the cytoskeleton as a possible culprit. As part of the case, students received fluorescence micrographs of the "victim's" kidney cells stained for actin and tubulin. In actuality, these were images of Cos-7 cells that had been treated with cytochalasin B, paclitaxel, or both. Students were then given cultures of Cos-7 cells and instruction on how to passage and maintain them. Using reagents and protocols provided, they devised experiments to compare and contrast the specific effects of several cytoskeletal disruptors, including colchicine (a microtubule disruptor), paclitaxel (a microtubule stabilizer), and cytochalasin B (an actin filament dis- ruptor), with the victim's micrographs. As a final product for evaluation, the students wrote a paper in which they proposed a solution to the mystery, by using both the class-generated data and the research literature to build their case. The drug or drugs with which the victim's cells were treated to produce the case micrographs were never revealed, so as to more closely approximate a scientific investigation in which the truth can be approached only through evidence and reasoning.

\section{Case 3: Microarrays}

The third case, which introduced a DNA microarray experiment, was inspired by the introduction to Chapter 6 in Malcolm Campbell and Laurie Heyer's textbook Discovering Genomics, Proteomics, $\mathcal{E}$ Bioinformatics (Campbell and Heyer, 2007). When a student tried to brew beer in her dorm room, the bottles exploded dramatically late one night while she was studying for a biochemistry midterm. At the same time, her eyes happened to fall on the title of the chapter to which she had just turned: "Yeast Metabolism: Fermentation versus Respiration." In a flash, she realized what must have gone wrong. The anecdote generally stimulated good class discussion about beer brewing, metabolic pathways, and the generation of carbon dioxide. After group research and reporting on these basics, it became clear that either the yeast continued to ferment sugar in the bottle (which can result from premature bottling or addition of excess priming sugar to induce carbonation) or that the yeast converted to aerobic metabolism and began to use the ethanol (this is only possible if the beer became aerated through sloppy handling during bottling).

The laboratory portion of this case module combined computation and bench work to distinguish between these possible explanations for the mishap. As an introduction to microarray data analysis, students received images from a yeast microarray hybridized with cDNA probes from the exploded beer yeast (which, the case explains, the home brewer had the foresight to collect) and from actively fermenting yeast as a reference. The students generated and explored gene expression ratios from the data using the open source program MAGIC Tool (Heyer et al., 2005). In the wet lab portion of the case module, students tested predictions about the gene expression changes that might accompany a shift to aerobic respiration by performing a series of microarray experiments on a yeast culture grown from low density to saturation. In late log phase, the cells transitioned from fermentation of the sugar in the medium to respiration of alcohol. This metabolic shift was the subject of a seminal paper on the use of DNA microarrays for monitoring gene expression changes (DeRisi et al., 1997). Protocols, microarrays, and scanning were obtained through the Genome Consortium for Active Teaching (www.bio.davidson.edu/gcat; Campbell et al., 2007).

\section{Case 4: Human Ancestry}

The fourth case was the story of a man named Bill Wong, who signed up for DNA testing to learn whether the family lore of descent from ancient Chinese rulers could be true. The choice of ethnicity was made in hopes of enhancing the engagement of students with Asian backgrounds. Test results were disappointing, however, because the two companies that analyzed his cheek swabs each sent back a different answer. The three kinds of analysis mentioned in the case involved sequencing the mitochondrial control region, checking tandem repeats on the $\mathrm{Y}$ chromosome, and testing for $A l u$ insertion polymorphisms. This set the stage for a discussion of how ancestry can be deciphered from genome sequences, the uncertainties and limitations of different approaches, ethical questions surrounding DNA testing, and even the reliability of companies that claim to test DNA.

To learn more directly about DNA testing, students isolated their own DNA and sequenced the first hypervariable sequence (HVS-1) of their mitochondrial control regions. HVS-1 polymorphisms are associated with discrete maternal lineages, or haplogroups, whose phylogeny and migration patterns have been 
extensively traced (Behar et al., 2007). Students also analyzed a subset of Alu insertion polymorphisms (students selected three of the eight described in Stoneking et al., 1997). Because most of these insertions occur on autosomes, where recombination complicates lineage tracing, and because nearly all occur throughout the world at varying frequencies, polymorphic Alu insertions are much less useful for ancestry work than mitochondrial DNA, as students quickly discovered. Y chromosome analysis (Underhill et al., 2000) was discussed in class, but we deemed tests to determine $\mathrm{Y}$ chromosome haplogroups, defined by widely dispersed polymorphisms, impractical given our time and resource limitations. Additionally, such experiments would have excluded any student not in possession of a Y chromosome.

Table 2. Assessment prompts and interview topics

Attitudinal assessment prompts (given at the beginning and end of the semester)

1. "If given the option in the future, I would choose to take a science class that uses case-based learning approaches over one that does not."

2. "I am committed to a career in biology research."

Videotaped interview sample questions

What aspects of the teaching approach of Bio 351 appealed to you?

What aspects of the teaching approach of Bio 351 were frustrating for you?

If you were to describe case-based learning and teaching to a friend, how would you describe it?

To what extent do you feel case-based learning was used in the Bio 351 class?

Do you feel more or fewer case-based modules would improve Bio 351? Why?

How (if at all) do you feel your participation in a case-based approach has affected your desire to pursue your science major/career?

Do you consider yourself to be a minority student with respect to language, ethnicity, religion, age, or gender?

If YES: To what extent do you feel like CBL is a more effective approach than the traditional approach for members of your minority group? If so, why?

If NO: Do you believe that CBL is more effective for certain categories of people? If so, which groups and why?

Module-specific learning assessment probes (asked before and after each module)

Case 1: Chick Cell Culture. "What are the critical aspects of designing a rigorous experiment?"

Case 2: Cytoskeletal Dynamics. "Describe ways in which the jobs of the actin and tubulin cytoskeletal systems can be teased apart experimentally."

Case 3: Microarrays. "Microarrays let researchers monitor the activity of thousands of genes at once. How would you explain to a time-traveling scientist from the 1980s the usefulness of microarrays to biomedical research today?"

Case 4: Human Ancestry. "How can we use DNA to trace the relationship of people living around the world today to a common ancestor who lived in Africa more than 100,000 years ago?"

Summative Learning Assessment Probe (given once at the end of the semester)

"What did you learn from your experiences in Bio 351 this semester that will continue to influence you for many years to come? How did you learn these things?"

\section{Assessment Methods}

We conducted four types of assessment in 2007, each of which is described below. Although 19 students were enrolled in the spring and 20 in the fall, not all students participated in each assessment. In addition, most assessments were performed in only one of the two semesters. The number of participants and timing were as follows: attitudinal assessments: spring, $\mathrm{n}=18$; videotaped interviews: spring, $\mathrm{n}=8$; module-specific learning assessments: fall; $\mathrm{n}=18-20$ (see Figure 2); and summative learning assessment: spring and fall, $\mathrm{n}=38$.

\section{Attitudinal Assessments}

To assess attitudes, we asked students to respond in writing to two statements, one statement about CBL and one statement about careers in science (Table 2). Responses were ungraded and anonymous. These in-class pre- and postassessments were conducted at the beginning and again at the end of the semester. Students included birth date or personal identification number on each response so that individuals could be matched before and after the semester. Before writing, students were given a brief definition of CBL (Waterman and Stanley, 2004) and then asked to rank their agreement with each statement on a Likert scale (1, disagree to 5 , agree).

\section{Videotaped Interviews}

Students were invited to participate in one-on-one interviews, which were conducted at the end of the semester. Eight students out of a class of 19 agreed to participate in spring 2007, the only semester in which interviews were conducted. Due to technical difficulties, one student's interview was not recorded. Excerpts from the remaining seven interviews can be found in Table 3 and in QuickTime Supplemental Videos 1 and 2 . The questions asked were designed to elicit students' attitudes toward the course and the use of cases. Each interview covered six general topics (Table 2 and Supplemental Material) and lasted $\sim 35$ min. The interviews were subsequently analyzed using a qualitative grounded theory approach to identify emergent themes and their prevalence among participants. Two to three student quotes were then selected to illustrate each concept (Table 3 and Supplemental Videos 1 and 2).

\section{Module-specific Learning Assessment}

To assess whether the CBL format could meet the learning goals of the course, we asked students to respond to a core content question before and after each case module (Table 2). Each question was administered in class on the day before (preassessment) the module began and the day after (postassessment) the module ended. Students were given $10 \mathrm{~min}$ to write a response. For example, the question for the microarray module was "Microarrays let researchers monitor the activity of thousands of genes at once. How would you explain to a time-traveling scientist from the 1980s the usefulness of microarrays to biomedical research today?" The questions were left intentionally broad to allow students maximum latitude in deciding what concepts were relevant. Responses were ungraded and anonymous. Students included a code on each response so that individual pre- and postassessments could be compared.

To score the responses, we created a list of concepts that were meant to be conveyed during the module and might be expected in response to the prompt. We then scored each answer for the number of concepts about which at least some understanding was indicated. A subset of responses was rescored independently by a second observer with similar results. The number of scored concepts varied from nine to 15 , depending on the case module. For example, the nine concepts for the microarray module that were mentioned by at least one student are as follows:

- Microarrays constitute a hypothesis-generating/unbiased approach to gene discovery. 
- The technology relies on hybridization of complementary sequences (or other details of array function).

- Arrays can monitor shifts in expression as a result of environmental changes/mutation.
- Arrays can be used to identify new genes in a cellular process or pathway.

- The method has applications beyond monitoring gene expression (student mentions at least one).

Table 3. Selected excerpts from videotaped interviews with undergraduate biology students

Emergent themes

On how CBL makes biology relevant (Supplemental Video 1)

On how CBL promotes scientific thinking (Supplemental Video 1)

On how CBL promotes learning from peers (Supplemental Video 1)

On how CBL promotes retention and synthesis of ideas (Supplemental Video 2)

On CBL as beneficial for minorities and English language learners (Supplemental Video 2)
Excerpts from student quotes

DAVID: “. . . before it was kind of like lab was just kind of a joke... When you have to figure it out, it kind of makes you more engaged ..."

ERICA: "I like the case-based approach where you think and you sort of design your own experiment ... It just seems much more relevant than the other lab classes."

BRENDA: "You know, in terms of medicine, it is case-based. You're drawing on so much knowledge to figure out why someone's thyroid is going haywire..."

FRANCIS: ". . . before he introduces the experiment we're going to be doing he kind of gives us ... a story behind it and ... it makes it ... more personal, like it applies to normal people ..."

"The first couple of labs we did it was based on ... this murder kind of like CSI . . I was like Cool! It's like being in the CSI lab."'

BRENDA: "Because it gives a context as to WHY you're doing something."

ERICA: "It's hard to learn and be engaged in a process that you know is meaningless, and this definitely was meaningful..."

ANA: “... it's ... a question about how you think ... scientifically in your lifestyle."

BRENDA: "Case-based for me has helped me in . . . broadening how I actually think about my problems at hand..."

"... . building a puzzle together and figuring out why something is going haywire ... same with research ... There's no protocol for you to follow. You have to figure out WHY your stuff's not going right."

ANA: "This is important for everybody ... to think scientifically."

HANS: "It's always about cooperation and group work... if you are in a group or if you are having a case-based study where you work with other people you are kind of motivated ..."

ERICA: "There's much more interaction between the people in the class ... and he switches up the groups and we really know each other by now ..."

ANA: "It's good to interact because you see how other people think and you come up with some ideas that you have never thought about..."

BRENDA: "When you do study groups you learn better that way because if you explain it to somebody you're reinforcing that you know your material so for me case studies does the same thing but ... on a personal level."

FRANCIS: "I guess when the teacher introduces the story you have to discuss it with your classmates and I guess it's easier to talk to classmates than to a teacher..."

"I know a lot of people that are shy ... they're afraid to go and talk to the teacher... so it makes it easier when you're discussing with students who are your own age ... you're not afraid to be shot down if you have ideas."

ANA: "When I study for the exam I can remember the questions that students were doing more than what the teacher was saying."

ANA: "The traditional way you learn a lot, like a lot of details. But then what do you remember after?" Instead in the interactive lecture ... you can remember the concepts much more."

HANS: ". . when you know more about ... what you're actually doing you memorize more."

BRENDA: "For me it was a way to see what I can and cannot recall from previous classes ..."

HANS: "So if you are a minority normally you don't ... talk a lot with a lot of people but if you're doing this case-based study then ... you enter into connections with other students and you get a lot of other inputs and views..."

FRANCIS: "Some Filipinos have language barriers and they ... already tune out when you lecture normally because ... they won't really understand it, they've got to go to the teacher directly, have them explain it again, so they don't really pay much attention at lecture but... with the case-based learning ... it makes it more interesting, more relevant to them. It's a situation that they can understand, relate to instead of just throwing them into something they might not get because of the language barrier."

GRETCHEN: “. . . it first came up that, Well okay I'm half Korean and half Scottish so I expect that I'll probably be heterozygous for PV92.'"

ERICA: ". . y you might be talking about a Hispanic woman who has a specific problem and then Hispanic people might relate to it more so then you're getting that variety. Rather than bland, generic data you're adding in some sort of spice to it ..."

ANA: “. . . basically you have just to take notes and read books so maybe it can be that more difficult for minorities maybe because they don't know the language."

GRETCHEN: "Well, I think that everybody has a different learning style and ... it's good that you're trying to find out what works for most people..." 
- Array data can be used to identify genes involved in disease processes.

- The tool is generally no more complicated than other gene expression assay methods.

- Coordinate regulation and possibly function of unknown genes can be inferred by clustering of expression patterns.

- Knowledge gained from microarrays can lead to drug development.

\section{Summative Learning Assessment}

Students were asked to type for 20 min during the penultimate class each semester on what they had learned. The prompt specifically asked for learning that would affect their lives "for years to come" (Table 2). Using a grounded theory approach, we analyzed responses for emergent categories of learning and scored the number of concepts about which the student claimed some understanding. Categories were kept intentionally broad to capture the spectrum of answers and to allow students to discuss their learning without being prompted in specific categories. Examples of emergent learning categories included working in groups, problem solving, and lab techniques.

\section{Course Context and Demographics}

Each of the assessments described above was carried out either in the spring or fall semester 2007. One of us (J.D.K.) instructed the course both semesters and also collected the learning data. Attitudinal and videotaped data were collected by R.M.F. In general, class demographics were reflective of the student body as a whole at SFSU, which, according to the university's Office of Budget and Planning, consists of $7 \%$ African Americans, 18\% Latinos, 36\% Asians and Pacific Islanders, and 34\% white non-Latinos.

Assessment data were collected with the approval of the SFSU Committee for the Protection of Human Subjects (protocol X7-008), and informed consent was obtained from each participant.

\section{RESULTS}

\section{General Impressions}

Few of the students in any class had taken a course that used CBL or PBL previously. As seniors, most students' expectations for lab courses were well ingrained. They were accustomed to receiving a lecture followed by a step-by-step laboratory session.

Possibly as a result, we initially encountered some resistance when we presented the cases and asked students to define their own areas of research. Each case scenario was described in a handout about a half-page long (see Supplemental Material for complete text of each case). After the case was read aloud in class, students were asked to list relevant concepts or facts they already knew as well as things they would need to find out to resolve the problem posed by the case. Each semester, presentation of the first two cases usually resulted in fairly anemic brainstorming, and students typically needed several attempts to develop a sufficient list of areas for further research.

One type of difficulty in generating "need to find out" items involved the understandable desire on the part of the students to learn more details about the case itself. Questions such as "What drugs did the chicken-raiser have in his medicine cabinet?" or "Had the murder victim been drinking?" were initially common. But the idea behind student research of questions about the case is to develop real-world explanations for the fictitious situation described. When such case-specific questions arose, we reiterated that further details of the case were not available and encouraged students to recast their questions in an investigable form. For example, if a student wanted to know the victim's blood alcohol level, we attempted to steer him or her toward a question such as "Do cytoskeletal disruptors interact with alcohol?"

By the third case in the semester, students were asking more interesting and varied questions during the initial brainstorm and had less trouble digging into the underlying issues. Although it is possible that students simply found the last two cases more compelling, we also informally noted a decrease in the number of noninvestigable questions as the semester went on, an outcome which should be independent of enthusiasm for the case.

Similarly, we informally noted a progression of research skills over time. As students attempted to answer the questions they had generated, they became more adept at searching the published literature as well as at identifying reliable sources of information on the Internet. Early on, Wikipedia had been both the first and the last stop for many students. We encouraged the use of Wikipedia mainly as a springboard to other lines of research, either through references provided in the entry or through ancillary topics mentioned. In-class research was more likely to break down into chatting and Web surfing during the earlier modules. To combat this tendency, we instituted same-day oral and written reports on research progress.

\section{Attitudinal Assessment}

Despite the time needed for students to warm up to CBL, their attitudes toward the pedagogy remained overwhelmingly positive (Figure 1). In spring 2007, students were given a brief definition of CBL (see Supplemental Material) and

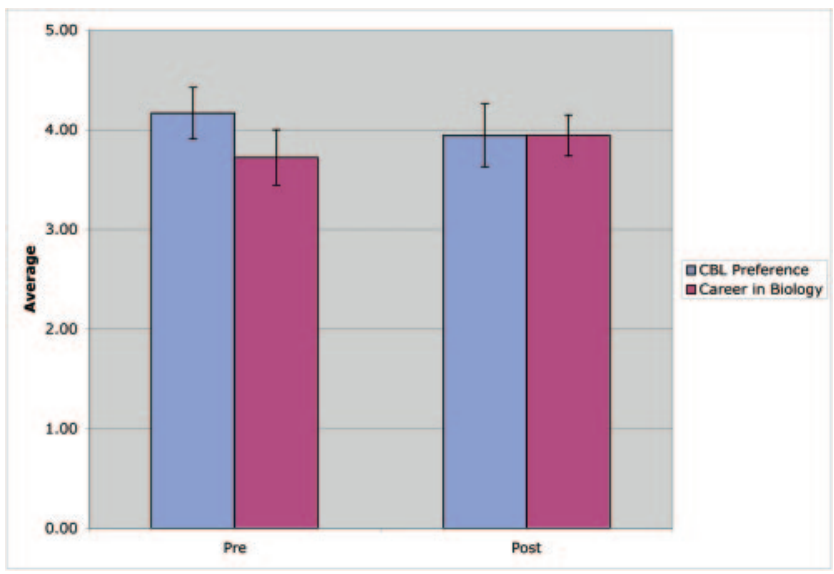

Figure 1. Students maintain a positive attitude toward CBL after four cases. Students enrolled in the spring semester 2007 were handed a printed definition of CBL (see Supplemental Material) and then asked to agree or disagree with two statements, the first regarding their interest in taking case-based courses in the future and the second regarding their commitment to a career in biology (see full text in Table 2). The prompts were given both at the beginning and the end of the semester, after the case modules had been completed $(n=18)$. Students ranked their agreement or disagreement on a Likert scale of 1 (disagree) to 5 (agree). 
asked to rank on a Likert scale from 1 to 5 their agreement with the statement, "If given the option in the future, I would choose to take a science class that uses case-based learning approaches over one that does not." At the beginning of the semester before any cases had been introduced, the average score was $4.17(\mathrm{n}=19 ; \mathrm{SE}=0.26)$, perhaps suggesting some excitement at the prospect of a new approach. After the completion of all four cases, the average remained essentially the same $(3.94 \pm 0.32)$. The high initial degree of enthusiasm for CBL even before any cases had been experienced suggested that students were eager to try a new approach. We took the maintenance of this strong enthusiasm for CBL at the end of the course as encouraging, given that such a large shift in pedagogy had the potential to frustrate students, particularly those nearing the end of their studies.

In addition, we asked them to agree or disagree with the statement, "I am committed to a career in biology research." Again, the initial class average score was quite high (3.72 \pm 0.28 ), as might be expected in an upper-division major course. In the postassessment, the average was slightly higher, but within the SE $(3.94 \pm 0.21)$. Again, there was no loss of enthusiasm after experiencing the CBL course. In keeping with this, two students commented in the videotaped interviews that the case-based modules had given them some insight into the nature of a research career, yet they were not at all dissuaded from their chosen path (data not shown).

\section{Videotaped Interviews}

Also in spring 2007, we conducted videotaped interviews of eight volunteers at the end of the course to assess student perception of the impact of CBL on their learning experience (see Table 2 and Supplemental Material). Table 3, which is hyperlinked to QuickTime movie files of the interviews, presents sample quotations from the interviews, each of which is hyperlinked to the original video clip from which it was taken. The names given are gender-specific pseudonyms.

Of the eight students interviewed, all but one student expressed a generally positive attitude toward CBL. That student said that the teaching style was not effective for her but that she could see its merits for other students. The learning themes that emerged from the student responses were in line with the anticipated benefits of the pedagogy. For example, CBL attempts to reach a broader range of students in part by connecting topical concepts to daily experience. Several of the students interviewed commented on this link.

ERICA: "I like the case-based approach where you think and you sort of design your own experiment... It just seems much more relevant than the other lab classes."

FRANCIS: "The first couple of labs we did it was based on ... this murder kind of like CSI ... I was like, 'Cool! It's like being in the CSI lab.'”

CBL also emphasizes the benefits of group work and social interaction as facilitators of learning and retention. Indeed, five of seven students interviewed commented on this aspect of the experience without being prompted.
ANA: "When I study for the exam I can remember the questions that students were doing more than what the teacher was saying."

HANS: “... if you are in a group or if you are having a case-based study where you work with other people you are kind of motivated..."

In comparing the case modules to their usual experience in lecture courses, students seemed to appreciate being forced to think.

BRENDA: "There's no protocol for you to follow. You have to figure out why your stuff's not going right."

For many of these reasons, students reported greater engagement with the material.

ERICA: "It's hard to learn and be engaged in a
process that you know is meaningless, and this
definitely was meaningful..."
DAVID: "... before it was kind of like lab was just
kind of a joke, just whatever - get through
it... When you have to figure it out, it kind of
makes you more engaged..."

ANA: "You can remember the concepts much more."

We also were interested in the student perception of whether CBL might speak to a broader base of students. Although we did not associate ethnic data with individual interviewees or their assessment data, the class reflected the diversity of SFSU as a whole, where $38 \%$ of students are African Americans, Native Americans, Hispanics, Filipinos, or Pacific Islanders. According to our own demographic survey of the spring 2007 class, seven of the 19 students' primary language was not English. Several students said they thought the case-based approach might be more accessible to members of minority groups, and one student commented specifically about English learners.

HANS: "So if you are a minority normally you don't ... talk a lot with a lot of people but if you're doing this case-based study then ... you enter into connections with other students and you get a lot of other inputs and views..."

ERICA: “. . y you might be talking about a Hispanic woman who has a specific problem and then Hispanic people might relate to it more, so then you're getting that variety."

FRANCIS: "Some Filipinos have language barriers and they ... already tune out when you lecture normally because ... they won't really understand it, they've got to go to the teacher directly, have them explain it again, so they don't really pay much attention at lecture but... with the case-based learning ... it makes it more interesting, more relevant to them. It's a situation that they can understand, relate to instead of just throwing them into something they might not get because of the language barrier."

\section{Module-specific Learning Assessment}

Our primary tool for assessing learning over the course of each case module was the paired pre- and postassessment question (Table 2). As expected, postassessments included a 


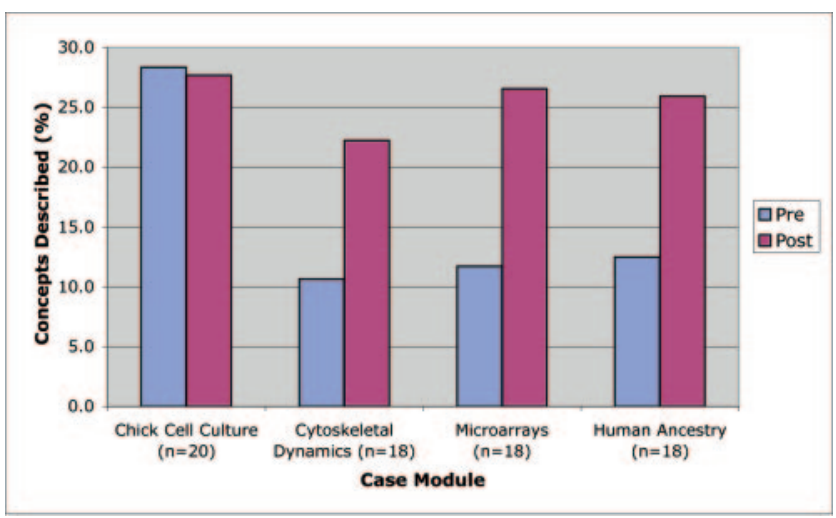

Figure 2. Module-specific learning assessment. In fall 2007, students responded to a core content question before and after each case module (text of questions is given in Table 2). Each question was administered in class on the day before (preassessment) the module began or the day after (postassessment) the module ended. Each response was scored against a list of concepts that were meant to be conveyed during the module and might be expected in response to the prompt. The average number of module concepts mentioned or discussed in each response is plotted here as a percentage of the total number of possible concepts.

greater degree of specific detail than the preassessment responses. We quantified this improvement by counting the number of relevant concepts mentioned in each response. We found that the average number of concepts scored per response roughly doubled for three of the four case modules (Figure 2). There was essentially no change, however, in the average score for the first module. This could have been a reflection of students' struggles with the new pedagogy. Alternatively, the question may have been insufficiently sensitive. Of the four, it was the least subject specific, and many students generated strong answers in the preassessment, thus limiting the potential for improvement.

\section{Summative Learning Assessment}

At the end of the spring and fall semesters 2007, Biology 351 students were asked to type for $20 \mathrm{~min}$ in response to the question, "What did you learn from your experiences in Bio 351 this semester that will continue to influence you for many years to come? How did you learn these things?" Responses were scored according to reported categories of learning.

Cases featured strongly in this open-ended assessment. Although lab techniques were mentioned more than any other category of learning (by $74 \%$ of students), 58\% mentioned CBL or a feature of that approach in describing what they learned (Figure 3, CBL categories). In addition, several types of learning that the case-based approach emphasizes scored highly as well. For example, $29 \%$ said they learned how to solve problems, and 58\% mentioned acquiring group work skills (Figure 3). This latter group consists of the $24 \%$ who referred specifically to case brainstorming and research (Figure 3, CBL-Group Work) added to the 34\% who referred only generally to the collaborative experience (Figure 3, Group Work). We kept these categories separate because, unless they specified, students may have been referring to the experimental work with their assigned lab partner-a feature in common with noncase-based laboratories.

Also of note was that most students (58\%) said they learned something about scientific writing and reading. Both have traditionally been important features in the course, but CBL placed additional emphasis on scientific communication. For example, students have always been required to write lab reports at the end of each module, but in the case-based version of the course they also produced written answers to case-inspired questions, and then shared and critiqued these in class or on the class website. Reading also became more important in our version of the course. Although laboratory reports for the course have always required a reference list, it has not been uncommon for students to cite papers based on their titles rather than their
Figure 3. Categories of learning reported in summative assessment. Students were given an open-ended prompt asking them to type for $20 \mathrm{~min}$ on the subject of what they had learned during the course and how they had learned it (see Table 2). The results shown here are from the spring and fall semesters of $2007(n=38)$. The three categories labeled CBL indicate that a specific reference to the case format was made in connection with the reported category of learning. The category Other included subjects such as ethics, how to rescue a failed experiment, and the theory behind techniques.

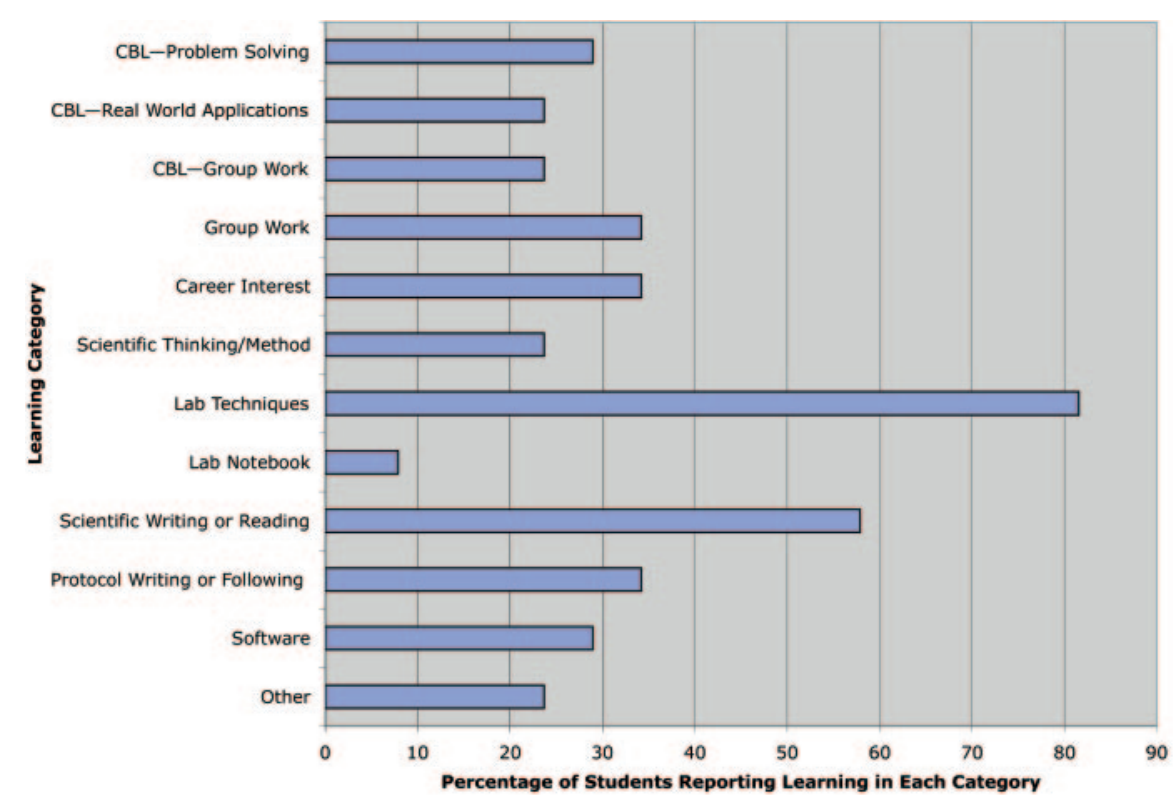

CBE-Life Sciences Education 


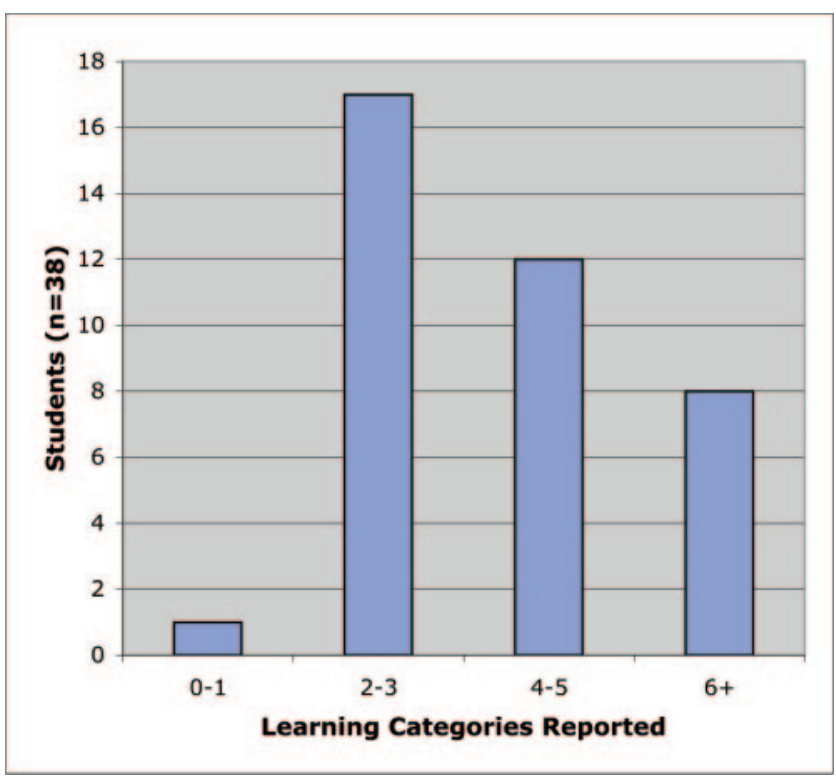

Figure 4. The majority of students reported multiple categories of learning in the summative assessments. The chart shows the number of students reporting either $0-1,2-3,4-5$, or $6+$ categories of learning in the summative assessment at the end of the semester. Data from two semesters were combined $(n=38)$.

content or relevance. Case research focused student literature searches by requiring them to find and restate answers.

Finally, to show that learning occurred in multiple categories for most students, we rescored the data as number of categories of reported learning per student. Half of the students in two semesters reported learning in at least four categories (Figure 4).

\section{DISCUSSION}

\section{Implementing Cases in a Laboratory Course}

Our experience indicates that introducing CBL into an existing laboratory course can be fairly straightforward. Although we took extra time initially to prepare each case, we have repeated the case modules described here several times with no more investment than a standard laboratory module requires. Furthermore, we found that no particular expertise was required to teach with cases. The instructor's only training in CBL was a 1-d workshop, conversations with instructors who had used cases, and a willingness to try and troubleshoot the approach.

Cases can be incorporated into existing laboratory modules without new supplies and reagents. For example, two of our case modules (chick cells and cytoskeletal dynamics) were joined to an existing classroom experiment. The original chick embryonic fibroblast lab focused on isolation of the primary culture and growth in the presence of compounds that alter cell adhesion. The twist we added was to ask students to choose their own compound after enough online research to allow them to make a prediction about its effect. This afforded them greater ownership of the experiment and gave their results at least indirect relevance to the case about environmental toxins and chickens. The cytoskeleton lab previously involved examining the effects of various cytoskeletal disruptors on cellular actin and tubulin networks. We connected this experiment to the case, which involved a murder, by providing students with fluorescence micrographs of the victim's cells stained for actin and tubulin. They could then use their experimental results to draw conclusions about the poison the victim consumed.

In a slightly different vein, the human ancestry lab had been carried out with some degree of open inquiry even before the case was added. Students were expected to work out for themselves what their mitochondrial DNA haplotype could and could not tell them, for example. The case about Bill Wong, a nonscientist trying to make sense of his DNA typing results, gave the questions broader context and helped students begin to think (and care) about them long before getting their own results. In addition, it tapped into strong feelings about ancestry that are found in the Chinese culture and among a number of other ethnic groups as well.

We found that attaching a case to an existing laboratory experiment was relatively risk free. The procedures and reagents were tried and true, so the chance of student error or a problem with reagents during the experimental portion of the case module was fairly low. Laboratory instructors using cases for the first time may find that preserving, or only slightly modifying, a trusted experiment will give the highest chance of smooth execution.

Even a greater risk of failure should not be a reason to avoid introducing new experiments or allowing greater student participation in experimental design. We found that students were remarkably able to come to terms with the discovery that experiments do not always work the first time. For example, the microarray experiment had never been performed in a classroom at this institution before its introduction in this course. Nor did we have the opportunity to optimize the procedures before the class. Students were made aware of this and understood that careful execution of the procedures would be important. Nevertheless, in a typical semester, about a third of the arrays generated little or no signal. Despite the students' obvious disappointment, some students commented in the videotaped interviews that they had learned a valuable lesson about the nature of the scientific process and the day-to-day work in their chosen career from such experiences (data not shown).

\section{Pedagogical Concerns}

One concern that has been raised about CBL is that students are likely to cover much less core course material if they do research on their own than if they listen to a carefully compiled lecture. The counterargument is that retention of course material soars in the active-learning setting, and students end up better able to apply their knowledge.

Although direct comparison of the two approaches was not possible, our learning assessments indicated that the case module goals were largely met. Furthermore, students responded to the open-ended prompt about what they had learned (summative learning assessment) by describing several learning categories that CBL emphasizes. Among these were problem solving (29\%), real-world applications (24\%), group work (58\%), and scientific thinking (24\%). More than a third said in the open-ended summative assessment that 
the course informed their interest in a career in biology research (Figure 3, Career Interest). Indeed, interest in CBL and careers in biological research remained strong at the end of the course.

Like many faculty who contemplate modifying their teaching style, we were concerned that students would respond poorly to the new pedagogy, particularly as many of them are graduating seniors who were used to a different format and seemed likely to shun new challenges in their home stretch. Thus the strong interest in CBL expressed in the attitudinal preassessments was surprising. A bit more in keeping with expectations, the introduction of the first case in class was met with quizzical looks and some reluctance to participate. The hesitation largely vanished within one or two class periods, and the attitudinal data bear out our perception that students came to find value in CBL.

Perhaps most encouraging were the strongly favorable attitudes toward CBL expressed in the videotaped interviews. Three points emerged from this data set that did not come out in other assessments. One point was the importance of relevance in biology teaching. Students reported much stronger engagement with the course content when it was framed in a familiar context. In addition, students placed tremendous value on the increased demand for them to communicate with one another. Also uniquely in the videotaped data, case relevance and peer learning emerged as useful strategies to make content more accessible to minority students.

Can CBL help stem the loss of students from science and engineering majors? To the extent that attrition in the sciences is partly driven by students' perception of poor teaching (Seymour and Hewitt, 1997), pedagogies that enhance engagement and sense of relevance, as our students reported, would be expected to ameliorate this effect somewhat. Active learning should logically have a greater impact on major selection when implemented in lower-division courses. It also could conceivably influence the career paths of upper-division students. The extent to which active learning promotes careers in science and engineering awaits further study.

We have attempted to show that CBL can readily be implemented in an upper-division laboratory course, that the concerns that deter some faculty from adopting CBL methods in their courses are ill-founded or readily overcome, that CBL meets learning goals, and that students respond favorably to the approach. It is our hope that instructors interested in trying a case-based approach will borrow, adapt, or modify the cases presented here. The cases can be used initially as introductions to well-established experiments, and then later they can be more closely intertwined with the laboratory module. For instructors interested in writing their own cases (see Supplemental Material for links to useful websites), we hope that these cases and our experience with them will serve as a springboard.

\section{ACKNOWLEDGMENTS}

We thank Dr. Janis Bunker for assistance in preparing course materials and for invaluable discussions and feedback about the cases. We are also grateful to Dr. Cynthia Fuhrmann for work on developing and implementing a trial version of the Bill Wong case. Dr. Joseph DeRisi generously provided microarrays, materials, scanner time, and expertise for the development of the microarray module. We also thank Dr. Michael DeFrietas (Molecular Devices, Sunnyvale, CA) for the donation of an Axon microarray scanner. Thanks also are due to Drs. Felipe-Andres Ramirez-Weber and Wilfred Denetclaw for willingness to discuss and collaborate on potential cases for the class. We are grateful to Drs. Ethel Stanley, Margaret Waterman, and Katayoun Chamany for the workshop on CBL at SFSU in December 2005. The workshop and much of the equipment and reagents used in the case modules were funded by CCLI grant DUE-0511697 from the National Science Foundation. We also greatly appreciate the willingness of students in the course to participate in the many assessments we performed. J.D.K. was involved in both the development of the cases and a portion of the assessment of learning outcomes.

\section{REFERENCES}

Allen, D., and Tanner, K. (2003). Approaches to cell biology teaching: learning content in context-problem-based learning. Cell Biol. Educ. 2, 73-81.

Behar, D. M., Rosset, S., Blue-Smith, J., Balanovsky, O., Tzur, S., Comas, D., Mitchell, R. J., Quintana-Murci, L., Tyler-Smith, C., and Wells, R. S. (2007). The genographic project public participation mitochondrial DNA database. PLoS Genet. 3, e104.

Campbell, A. M., and Heyer, L. J. (2007). Discovering Genomics, Proteomics, and Bioinformatics, San Francisco, CA: Benjamin Cummings.

Campbell, A. M., et al. (2007). Genome consortium for active teaching: meeting the goals of bio2010. CBE Life Sci. Educ. 6, 109-118.

Chamany, K. (2006). Science and social justice: making the case for case studies. J. Coll. Sci. Teach. 36, 54-59.

Chamany, K., Allen, D., and Tanner, K. (2008). Making biology learning relevant to students: integrating people, history, and context into (college) biology teaching. CBE Life Sci. Educ. 7, 267-278.

DeRisi, J. L., Iyer, V. R., and Brown, P. O. (1997). Exploring the metabolic and genetic control of gene expression on a genomic scale. Science 278, 680-686.

DiCarlo, S. E. (2006). Cell biology should be taught as science is practised. Nat. Rev. Mol. Cell Biol. 7, 290-296.

Handelsman, J. et al. (2004). Scientific teaching. Science 304, 521-522.

Hayes, R. Q. (2002). 2001-02 Stem Retention Report: The Retention and Graduation Rates of 1994-2000 Freshman Cohorts Entering Science, Technology, Engineering and Mathematics Majors in 200 Colleges and Universities. Norman, OK: Consortium for Student Retention Data Exchange.

Heyer, L. J., Moskowitz, D. Z., Abele, J. A., Karnik, P., Choi, D., Campbell, A. M., Oldham, E. E., and Akin, B. K. (2005). Magic tool integrated microarray data analysis. Bioinformatics 21, 2114-2115.

Howard, D. R., and Miskowski, J. A. (2005). Using a module-based laboratory to incorporate inquiry into a large cell biology course. Cell Biol. Educ. 4, 249-260.

Rath, K. A., Peterfreund, A. R., Xenos, S. P., Bayliss, F., and Carnal, N. (2007). Supplemental instruction in introductory biology I: enhancing the performance and retention of underrepresented minority students. CBE Life Sci. Educ. 6, 203-216.

Regassa, L. B., and Morrison-Shetlar, A. I. (2007). Designing and implementing a hands-on, inquiry-based molecular biology course. J. Coll. Sci. Teach. 36, 36-41.

Seymour, E., and Hewitt, N. M. (1997). Talking about Leaving: Why Undergraduates Leave the Sciences, Boulder, CO: Westview Press. 
Stanley, E. D., and Waterman, M. A. (2000). "Lifelines online"curriculum and teaching strategies for adult learners. J. Coll. Sci. Teach. 29, 306-310.

Stoneking, M., et al. (1997). Alu insertion polymorphisms and human evolution: evidence for a larger population size in Africa. Genome Res. 7, 1061-1071.

Summers, M. F., and Hrabowski, F. A., 3rd. (2006). Preparing minority scientists and engineers. Science $311,1870-1871$.
Underhill et al. (2000). Y chromosome sequence variation and the history of human populations. Nat. Genet. 26, 358-361.

Waterman, M. A., and Stanley, E. D. (2004). Doing science collaboratively with investigative case-based learning. Strateg. Success: 41 , $4-6$.

Wright, R., and Boggs, J. (2002). Learning cell biology as a team: a project-based approach to upper-division cell biology. Cell Biol. Educ. 1, 145-153. 